\title{
The Impact of Federal Reserve Bank (FRB) Monetary Policy on NIEs
}

\author{
Yi Sun \\ Shandong University of Technology, Zhangdian District, Zibo, Shandong, China
}

Keywords: NIEs, the US M2/GDP, capital flow.

\begin{abstract}
A few years ago when large-scale capital outflow occurred, NIEs countries always had large-scale international short-term capital inflows and their domestic capital markets prospered. This paper first describes the calculation method of international short-term capital inflows, and then makes descriptive statistics on the data of M2 / GDP in the United States from 1994 to 2015 with the flow of international short-term capital in NIEs countries. It is concluded that the FRB expansionary and tightening monetary policy is closely related to the massive inflows and outflows of the national capital in many NIEs countries.
\end{abstract}

\section{Introduction}

In the early 1990s, large-scale capital inflows to NIEs promoted the economic prosperity of NIEs. However, from the Mexican financial crisis in 1994 to the outbreak of the Asian financial crisis in 1997, various NIEs countries have also experienced the economic fluctuations brought about by the large-scale withdrawal of international short-term capital. Therefore, we use the data from the outbreak of the Mexican financial crisis in 1994 to the year 2015 when the United States withdrew from the quantitative easing policy.

Since the dollar is of great importance and have huge influence, if interest rates rise or fall, it may cause massive outflow of capital inflows in newly industrialized countries. The adjustment of US dollar interest rates first acts on the contraction or expansion of M2 in a country, and M2 is the most direct manifestation of the liquidity tightness of developed countries. Therefore, we use the data of M2 / GDP in the United States to analyze the correlation between the fluctuation of the US dollar and the short-term capital flows of the NIEs.

\section{Literature Review}

The reversal of capital inflows commonly happens when there is a large amount of foreign capital inflows into developing countries in the early stage. The dollar accounted for $60 \%$ of the world`s exchange reserves, which play an important role in capital market. Therefore, the dollar exchange rate changes significantly influence the stability of developing countries.

Calvo (1993) found that external factors such as the economic cycle in developed countries, the world interest rate etc can explain $30-60 \%$ of the changes in the real exchange rate and foreign exchange reserves of Latin American countries, thus they put forward that the main driving force of capital inflows and reversal is the external factors.

Huang Xiaolong (2007) and Zhang Chunwei (2007) pointed out that the adjustment of interest rates and exchange rates in the United States have an important impact on capital flows in developing countries, and the exchange rate adjustment is realized through the interest rate adjustment.

Li Daokui (2009) found that what played an important role in adjusting dollar interest rate was M2, and held the opinion that financial crisis in newly industrialized countries was induced by the external factors (economic conditions in developed countries) through the internal factors in developing countries.

Chapter 1: Introduction to NIEs National Concepts and International Short-Term Capital Calculation Formulas. NIEs National Concepts. Newly industrialized Economies (abbreviation: NIEs) mean the countries whose economic development is between developed and developing 
countries. The name was put forward in the <report of the organization for economic cooperation and development> in the late 1970s. In short, the newly industrialized economies are the developing countries with some capitalism base, who overcomed the backwardness of social economy in a short period and developed close, although not as much, to the developed countries in the process of industrialization. The newly industrialized economies include South Africa, Mexico, Brazil, China, India, Indonesia, Malaysia, Philippines, Thailand, Turkey.

International Short-Term Capital Calculation Formulas. After the outbreak of the Asian financial crisis in 1997, NIEs countries (except Turkey) have imposed controls, but in the real economy, it is often difficult to accurately calculate the international short-term capital inflows, such as short-term capital for the foreign exchange market and other illegal means to flow, which is not the exact statistical data. Although international short-term capital can be roughly estimated from the balance of payments, the results can only represent part of real capital flows, far from complete and accurate. Therefore, estimating the scale of international short-term capital flows has been more controversial. Zhang Ming (2011) systematically analyzed and evaluated various estimation methods of short-term international capital flow, and then used the direct method and indirect method to estimate the short-term international capital flows of China. Both In the direct method and the indirect method, he used three kinds of caliber from the narrow to the wide. In the estimation process, full consideration is given to short-term international capital flows through trade, other current account items, capital account items, errors and omissions. The estimation results show that although the measurement results of different caliber under different methods are different, these estimation methods are highly consistent in a certain period. Finally, it concludes that none of these methods is very rigorous and perfect. But as long as the method is adopted for a long time, the general trend of short-term international capital flow can be grasped.

Therefore, due to the irregularities in the flow channels of current international short-term capital inflow, and the complexity of calculating the short-term capital itself, this paper chooses a relatively simple formula of international capital calculation.

Speculative short-term capital = the amount of foreign exchange reserves - trade surplus - FDI (foreign direct investment)

Since this article uses the data of 1994-2015, which is a long time span, this formula is not that accurate, but we can grasp the general trend of the scale of international short-term capital flow. Therefore, the method of calculation has certain practical significance of international short-term capital flow.

Chapter 2: A Joint Analysis of M2/GDP in the U.S and the Short-term Capital. Annual data for 1994-2015 were found at the IMF and the World Bank. According to the analysis, some countries are sensitive to the changes in the US M2 / GDP and the changes in the major time points are consistent. However, in some countries, only certain stages have the same trend with M2 / GDP. The reason is closely related to the economic fundamentals of these countries themselves. Economic structure and policies will largely affect the sensitivity of a country to changes in U.S. policy.

Through the analysis, it is found that the international short-term capital flows in Indonesia, Mexico, Turkey and China Mainland are in clear agreement with the fluctuations in the U.S. dollar M2 / GDP.

\subsection{The international short-term capital flows in Indonesia, Mexico, Turkey and China Mainland are in clear agreement with the fluctuations in the U.S. dollar M2 / GDP}

Data source: World Bank's World Development Indicator Database

Through the figure 1 and 2, we can see:

1) Before 2012, with the exception of 2005-2007, the U.S. economic bubble was extremely large in these three years. The global economy was prospering. The international financing of NIEs was smooth and inflows of hot money followed. Although the U.S. dollar continues to raise interest rates, the international short-term capital still has an inflow trend. In other years, the international short-term capital flows in Indonesia, Mexico, Turkey and China Mainland are largely in line with changes in the U.S. dollar M2 / GDP. 
2) After 2012, although the dollar has risen all the way, the expected dollar withdrawal from QE is getting stronger. After 2012, the drop in gold prices is an important sign. In December 2014, the United States announced its official withdrawal from the quantitative easing policy. The expected appreciation of the U.S. dollar has been significantly strengthened. Short-term international capital in Indonesia, Mexico, Turkey and China Mainland also fled.

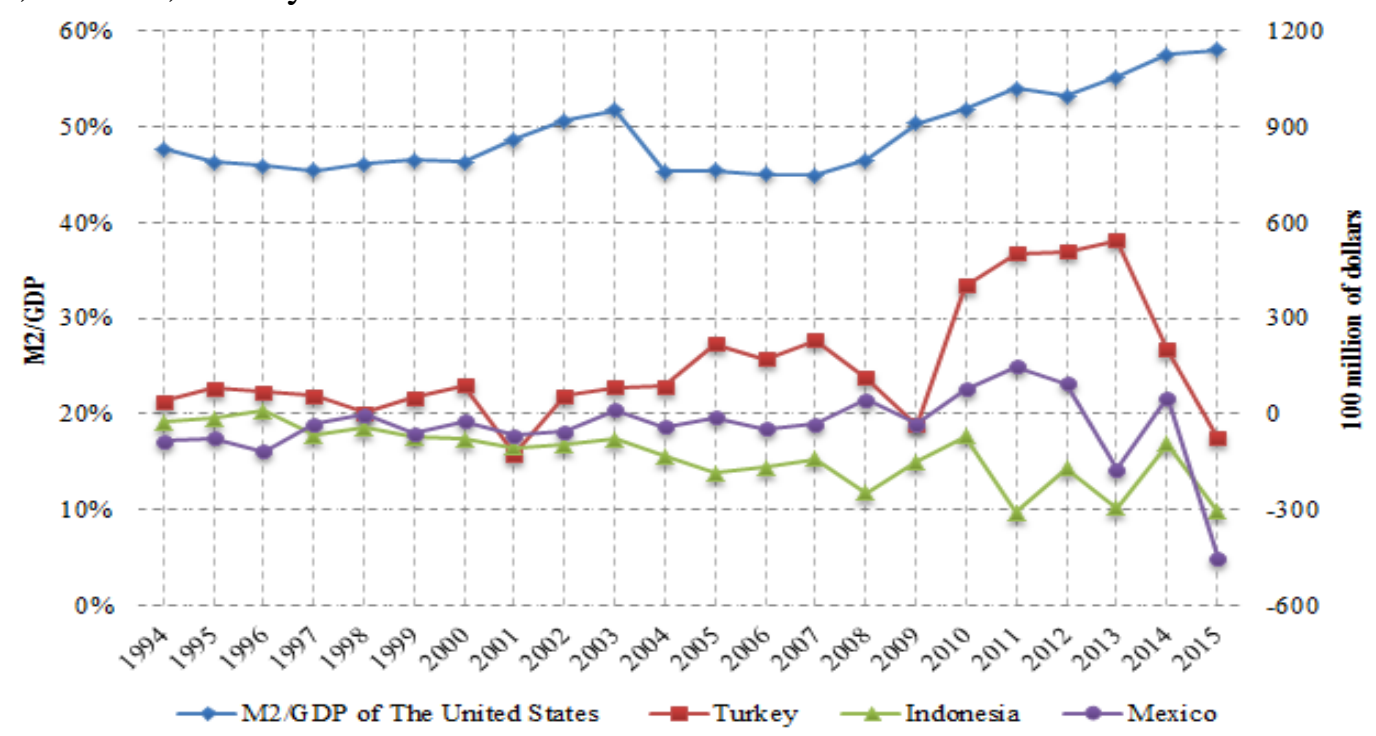

Figure 1: The joint of the dollar M2 / GDP and the international short term inflow in Indonesia, Mexico, Turkey

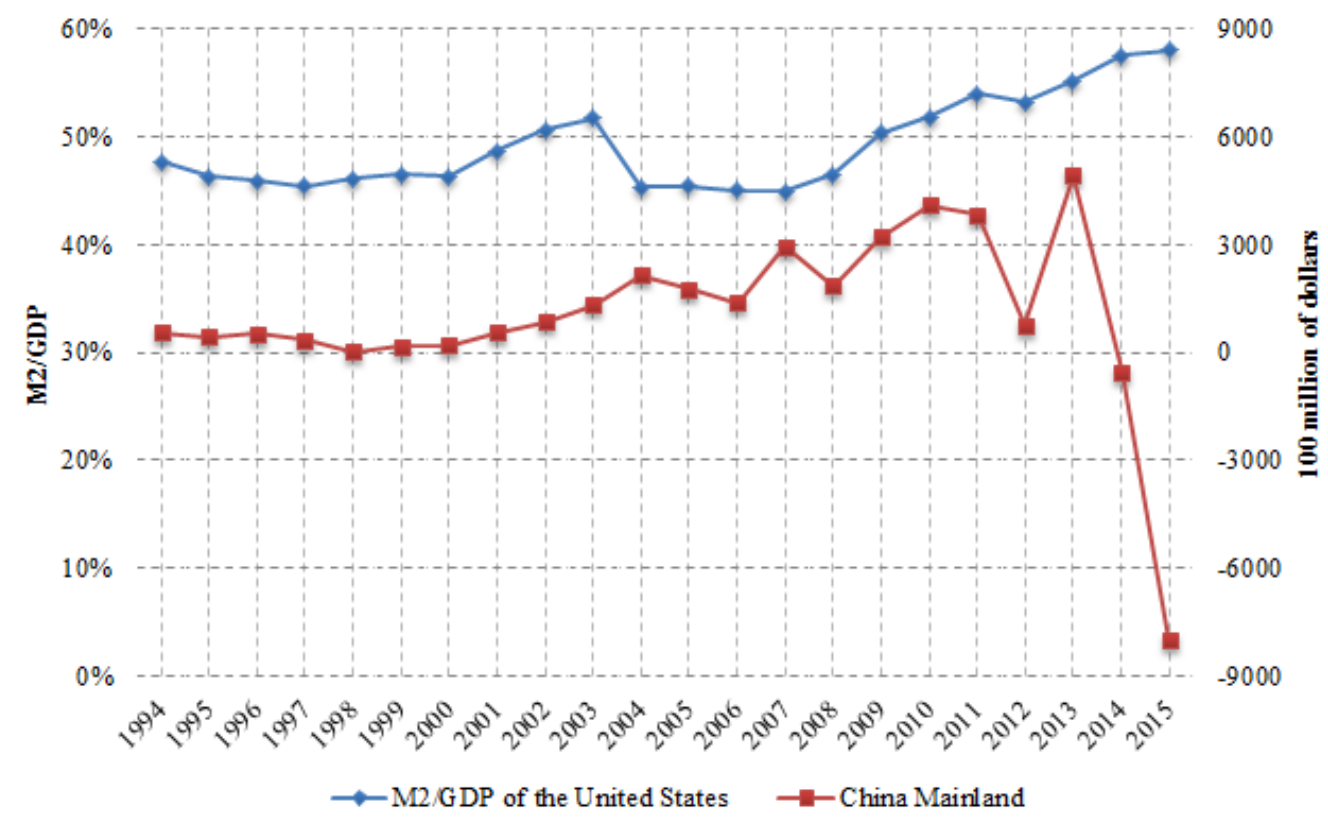

Figure2: The joint of the dollar M2 / GDP and the international short term capital inflow in China Mainland

\subsection{Certain stages in Thailand and South Africa have the same trend with M2 / GDP}

In some countries, the economic fluctuations in NIEs are only related to the fluctuation of M2 / GDP in stages, such as Thailand and South Africa.

Data source: World Bank's World Development Indicator Database from figure 3, we can know that:

It is well-known that the financial crisis in Thailand was closely linked with the long-term decline in the M2 / GDP of the United States in 1997. We can see from the figure that the international short-term capital flows in Thailand were closely related to the dollar M2 / GDP in 1998-2002, 
international short-term capital outflow as a result of the U.S financial crisis in 2009, and the trend of international capital flight evidently under the expectation of the appreciation of the U.S. dollar in 2013 and 2015. However, despite the declining trend in 2003 and 2007, the trend in other years in 2003-2007 is steady. After 2008, the United States adopted the policy of quantitative easing. Thailand has only a short period of small-scale capital inflows, and has been an overall declining trend. It is not only because of the expectation of appreciation in U.S, but also Thailand's regulation of international short-term capital inflows and its policy of encouraging capital outflow.

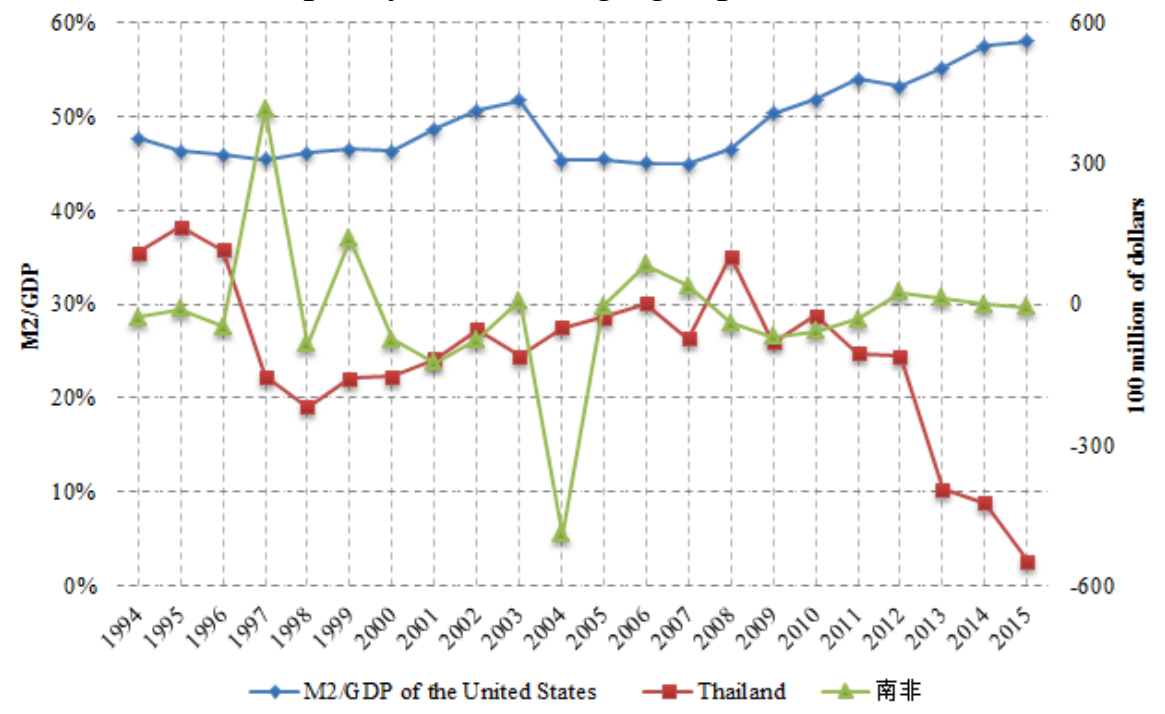

Figure 3: The joint of the dollar M2 / GDP with the international short term capital inflow in Thailand and South Africa

Short-term international capital flows in South Africa were closely related to the fluctuation of M2 / GDP in the United States prior to the financial crisis in 2008, but the persistent downturn in the inflow (below 0 in the long run) after 2008, is in line with South Africa's economic recession.

\section{References}

[1] Calvo, G; Leiderman, L. and Reinhart, C, Capital Inflows and Real Exchange Rate Appreciation in Latin America, IMF Staff Papers, 1993, Vol.40, pp.108 -151

[2] Edwards, Sebastian, Capital Controls, Sudden Stops and Current Account Reversals, IMF Working Paper, 2004.

[3] Izquierdo, Alejandro; Romero, Randall and Talvi, Ernesto, Booms and Busts in Latin America: The Role of External Factors, IMF Working Paper, 2007.

[4] Kanit Sangsubhan, Managing Capital Flows: The Case of Thailand”, ADB Institute Discussion Paper No. 95, March 2008.

[5] Huang Xiaolong, Global imbalances, excess liquidity and currency crises - based on a non-equilibrium analysis of the international monetary system perspective, Financial Research, No. 8, 2007, pp. 31-46.

[6] Zhang Chunwei, The Dollar Standard, Valuation Effects and Monsoon Crisis, Financial Research, No. 3, 2007, pp. 50-61.

[7] Li Daokui, US dollar M2 tightening induced world financial crisis: internal and external financial crisis theory and test, World Economy, No. 4, 2009, pp.11-26.

[8] Zhang Ming, China's Short-term International Capital Flow: Estimation Based on Various Methods and Levels, World Economy, No. 2, 2011. 